\title{
Delayed brainstem auditory evoked potential latencies in 14-year-old children exposed to methylmercury
}

\section{Citation}

Murata, Katsuyuki, Pál Weihe, Esben Budtz-Jørgensen, Poul J Jørgensen, and Philippe Grandjean. 2004. "Delayed Brainstem Auditory Evoked Potential Latencies in 14-Year-Old Children Exposed to Methylmercury." The Journal of Pediatrics 144 (2) (February): 177-183. doi:10.1016/j.jpeds.2003.10.059.

\section{Published Version}

doi:10.1016/j.jpeds.2003.10.059

\section{Permanent link}

http://nrs.harvard.edu/urn-3:HUL.InstRepos:34787242

\section{Terms of Use}

This article was downloaded from Harvard University's DASH repository, and is made available under the terms and conditions applicable to Other Posted Material, as set forth at http:// nrs.harvard.edu/urn-3:HUL.InstRepos:dash.current.terms-of-use\#LAA

\section{Share Your Story}

The Harvard community has made this article openly available.

Please share how this access benefits you. Submit a story.

Accessibility 
Manuscript submitted to Journal of Pediatrics (MS 2300444, accepted for publication)

\section{Delayed brainstem auditory evoked potential latencies in 14-year-old children exposed to methylmercury}

Katsuyuki Murata, MD, DMSc, Pál Weihe, MD, Esben Budtz-Jørgensen, PhD, Poul J Jørgensen, MSc, and Philippe Grandjean, MD, DMSc

From the Division of Environmental Health Sciences, Akita University School of Medicine, Akita, Japan; the Department of Occupational Medicine and Public Health, Faroese Hospital System, Tórshavn, Faroe Islands; the Department of Biostatistics, Institute of Public Health, University of Copenhagen, Copenhagen, Denmark; the Institutes of Clinical Research and Public Health, University of Southern Denmark, Odense, Denmark; and the Department of Environmental Health, Harvard University School of Public Health, Boston.

Supported by the National Institute of Environmental Health Sciences (ES09797), the Danish Medical Research Council and the Nissan Science Foundation. The contents of this paper are solely the responsibility of the authors and do not represent the official views of the NIEHS, NIH or any other funding agency.

Reprint requests: Philippe Grandjean, MD, Department of Environmental Health, Harvard School of Public Health, Landmark Center East room 3-110, 665, P.O.Box 15967, Boston, MA 02115.

Correspondence to: Philippe Grandjean, Institute of Public Health, University of Southern Denmark, Winsløwparken 17, 5000 Odense C, Denmark. Phone: +45-65503768. Fax: +45-65911458. Email: pgrand@hsph.harvard.edu 
Key words: Evoked potentials, auditory Environmental pollution Food contamination Methylmercury compounds Prenatal exposure delayed effects

Objective: To determine possible exposure-associated delays in auditory brainstem evoked potential (BAEP) latencies as an objective measure of neurobehavioral toxicity in 14-year-old children with developmental exposure to $\mathrm{MeHg}$ from seafood.

Study design: Prospective study of a birth cohort in the Faroe Islands, where 878 of eligible children (87\%) were examined at age 14 years. Latencies of BAEP peaks I, III, and V at 20 and $40 \mathrm{~Hz}$ constituted the outcome variables. Mercury concentrations were determined in cord blood and maternal hair, and in the child's hair at ages 7 and 14 .

Results: Latencies of peaks III and V increased by about $0.012 \mathrm{~ms}$ when the cord-blood mercury concentration doubled. As seen at age 7, this effect appeared mainly within the I-III interpeak interval. Despite lower postnatal exposures, the child's hair-mercury level at age 14 years was associated with prolonged III-V interpeak latencies. All benchmark dose results were similar to those obtained for dose-response relationships at age 7 years.

Conclusions: The persistence of prolonged I-III interpeak intervals indicates that some neurotoxic effects from intrauterine $\mathrm{MeHg}$ exposure are irreversible. A change in vulnerability to $\mathrm{MeHg}$ toxicity is suggested by the apparent sensitivity of the peak III-V component to recent MeHg exposure. 
BAEP Brainstem auditory evoked potential

BMD Benchmark dose

BMDL Benchmark dose level

BMR Benchmark response

CV Coefficient of variation

EP Evoked potential

$\mathrm{MeHg} \quad$ Methylmercury

NRC National Research Council

PCB Polychlorinated biphenyl 
Methylmercury $(\mathrm{MeHg})$ is a worldwide contaminant of seafood and freshwater fish. ${ }^{1} \mathrm{MeHg}$ toxicity can produce widespread adverse effects within the nervous system, especially when exposures occur during brain development. ${ }^{2-3}$ Early adverse effects have been characterized by administering neurobehavioral tests to children exposed in utero from maternal seafood diets. ${ }^{4-6}$ Thus, a National Research Council (NRC) committee $^{7}$ recently concluded that intrauterine $\mathrm{MeHg}$ exposure was the most critical and emphasized the findings from a prospective birth cohort study carried out in the Faroe Islands. ${ }^{5}$ The damage to the developing nervous system is thought to be potentially irreversible. ${ }^{7}$ The possibility also exists that exposure during postnatal development may induce brain lesions; clinical $^{2,8}$ and experimental ${ }^{9}$ information suggests that such effects would tend to be more focal and particularly involve the sensory cortex and the granular layer of the cerebellum.

Current advisories on fish consumption issued by national and state authorities differ and mainly aim at pregnant women or women of reproductive age groups. ${ }^{1}$ Because the risk to children from dietary MeHg exposure is unclear, some fish advisories in the US also address 'young children', ${ }^{10}$ or children up to, e.g., 8 years ${ }^{11}$ or 15 years. ${ }^{12}$

As an indicator of $\mathrm{MeHg}$ neurotoxicity, delayed evoked potential (EP) latencies have been recorded in poisoning victims ${ }^{13,14}$ and in laboratory animals. ${ }^{15}$ In contrast to neuropsychological test outcomes, this measure is thought to be independent of socioeconomic covariates. ${ }^{16}$ As illustrated by environmental exposure to lead, EP abnormalities constituted important objective evidence on neurotoxic effects in children. ${ }^{17}$

In an extended follow-up of the Faroese birth cohort, we have assessed brainstem auditory evoked potentials (BAEPs) at age 14 years. We previously showed that increased intrauterine $\mathrm{MeHg}$ exposures were associated with delayed peak III latencies at age 7 years. ${ }^{5,18}$ We hypothesized that these delays would remain at age 14 and that BAEP latencies would also 
be sensitive to $\mathrm{MeHg}$ from adolescent seafood diets.

\section{METHODS}

\section{Study Population and Follow-up}

A cohort of 1,022 births was assembled in the Faroe Islands during a 21-month period of 1986-1987. ${ }^{19,20}$ The primary indicator of intrauterine exposure to MeHg was the mercury concentration in cord blood, and concentrations in maternal hair at parturition were also determined. ${ }^{19}$ MeHg exposures varied considerably: 15\% of the mothers had hair mercury concentrations above $10 \mathrm{~g} / \mathrm{g}$, while $4 \%$ were below $1 \mathrm{~g} / \mathrm{g}$, a level that corresponds to the exposure limit recommended by the NRC committee. ${ }^{7}$ Concomitant exposure to polychlorinated biphenyls (PCBs) was determined from the concentration in umbilical cords from 438 cohort members. ${ }^{5}$ The first follow-up examination was carried out seven years later and included hair-mercury assessment, evoked potentials and pediatric examination., ${ }^{5,21}$

At age 14 years, a total of 878 of 1,010 live cohort members $(86.9 \%)$ were examined. Most examinations took place at the National Hospital in Tórshavn, the capital of the Faroe Islands, during April-June of 2000 and 2001. For families who had moved, examinations were also offered in Odense, Denmark in November 2000. Each day, four children were examined during the morning, and four during the afternoon. The examinations were conducted by a team of health professionals who had no access to information on individual exposure levels. The 438 boys and 440 girls examined had an average age of 13.83 (SD, 0.32) years.

Hair samples were again obtained, and the proximal 2-cm segment was analyzed by flow-injection cold-vapor atomic absorption spectrometry after digestion of the hair sample in a microwave oven. ${ }^{5}$ The total analytical imprecision for this analysis was estimated to be $4.3 \%$ and $5.5 \%$ at mercury concentrations of $4.7 \mathrm{~g} / \mathrm{g}$ and $11.1 \mathrm{~g} / \mathrm{g}$, respectively. Accuracy was 
ensured by participation in the Canadian Hair Mercury Quality Control Program; all our results were within one SD of the adjusted mean. The high analytical quality is comparable to previous performance. $^{5,19}$ Results in $\mathrm{g}$ may be converted to nmol by multiplying by 5.0 .

The study protocol was approved by the ethical review committee for the Faroe Islands and the institutional review board at the U.S. institution, and parental informed consent was obtained.

\section{Neurological examination}

A thorough pediatric examination included otoscopy and assessment of neurological optimality. None of the children had current middle ear infection. A total of 18 children examined had neurological disorders thought to be independent of $\mathrm{MeHg}$ exposure and were therefore excluded from the data analysis: Congenital hypothyreosis, 1; Gilles de la Tourette's syndrome, 1; dystonia, 3; epilepsia, 2; polyneuropathy sequelae, 1; mental retardation, 1; psychomotor retardation, 4; meningitis sequelae, 1 ; concussion, 3 ; and deafness, 1 . None of the subjects examined had diabetes. The MeHg exposure of these subjects did not differ from that of other cohort members.

BAEPs were determined in all participating subjects, except for one refusal $(\mathrm{N}=859)$. We used a four-channel electromyograph (Medelec Sapphire-4ME) also employed previously. ${ }^{5,21}$ Click signals at an intensity of $65 \mathrm{~dB}$ HL ( $0.1 \mathrm{~ms}$ impulses of alternating polarity) were presented to the right ear through shielded ear phones at $20 \mathrm{~Hz}$ and $40 \mathrm{~Hz}$ (sampling time, $0.01 \mathrm{~ms}$ ); the other ear was masked with white noise at an intensity of $45 \mathrm{~dB}$ HL. A frequency of $50 \mathrm{~Hz}$ was also attempted, but peak I was poorly defined at this click rate. EPs were recorded using three standard EEG electrodes placed on the vertex, the right mastoid ipsilateral to stimulation and the left mastoid (ground). While 1,024 responses were used seven years before, ${ }^{5,21}$ the number was increased to 2,048 to improve the definition of peak I. Amplification and filtration were 
unchanged, and one replication of each condition was again carried out for calculation of average peak latencies. The coefficients of variation (CVs) for duplicate assessments remained higher for peak I (mean, $8.4 \%$ ) than for peaks III and V (means, $4.3 \%$ and $3.7 \%$, respectively). As an additional part of the quality assurance, latencies from the first 250 children examined in Tórshavn in 2000 were scored twice by the same examiner $(\mathrm{KM})$. The results of this blinded scoring-rescoring showed average CVs of $8.9 \%, 4.4 \%$, and $3.7 \%$ for peaks I, III, and V, i.e. similar to the duplicate assessments. Thus, although highly appropriate for latency measurement, the study circumstances did not allow accurate assessment of peak amplitudes. Peaks I, III, and V are thought to reflect the volume-conducted electric activity from the acoustic nerve, pons (superior olivary nucleus), and midbrain (inferior colliculi), respectively. ${ }^{16}$

Audiometry was carried out by a trained nurse using Interacoustics Diagnostic Audiometer AD229 with a Peltor H7A headphone in a sound-insulated room. The patient-controlled Hughson-Westlake procedure was used in accordance with ISO 8253-1. A threshold was defined as two out of three correct responses in a procedure with $5 \mathrm{~dB}$ increases and $10 \mathrm{~dB}$ decreases. Pure-tone air-conduction hearing thresholds were measured at 125, 250, $500,750,1000,1500,2000,3000,4000,6000$, and $8000 \mathrm{~Hz}$. Two children did not complete their audiometry examination.

\section{Data analysis}

Pearson's correlation coefficients were used to assess bivariate relationships between exposure parameters. Regression analysis was used to determine the association of $\mathrm{MeHg}$ exposure with the outcome variables. Age and sex may be important predictors of BAEP latencies ${ }^{16,21}$ and were therefore included as independent variables along with the exposure parameters. In addition, confounders previously included in the analysis of neuropsychological test results ${ }^{5}$ were 
screened for possible associations with the outcomes in the present study, but no pattern was found. Further models included as an independent variable the latency result obtained 7 years previously along with the age at that examination. Additional analyses also incorporated PCB and postnatal MeHg exposure parameters as explanatory variables. Because of skewed distributions, logarithmic transformation of the contaminant concentrations was used, and the mercury regression coefficients therefore correspond to the change in the dependent variable associated with a 10-fold increase in $\mathrm{MeHg}$ exposure. Significant exposure effects were further explored in generalized additive models, which do not require linearity assumptions while providing a smooth nonparametric dose-response curve. ${ }^{22}$

Calculation of the benchmark dose (BMD) is increasingly used for comparison of dose-response curves at low dose levels and for determining exposure limits. ${ }^{7,18}$ The BMD is the dose of a substance that increases the risk of an abnormal response by a benchmark response (BMR), i.e., from $\mathrm{P}_{0}$ (usually $5 \%$ ) for an unexposed child to $\mathrm{P}_{0}+\mathrm{BMR}$ for a child exposed at the BMD. ${ }^{23}$ The NRC committee used a BMR of $5 \%$ so that an exposure at the corresponding BMD will double the risk of an abnormal response. ${ }^{7}$ To take the statistical uncertainty into account, a lower 95\% confidence limit (BMDL) for the BMD is also determined. Using linear dose-response models, BMDLs expressed as the maternal hair mercury concentration were about $10 \mathrm{~g} / \mathrm{g}$ for the most sensitive neuropsychological and BAEP outcomes in the Faroese children at age 7 years. ${ }^{7,18,24}$ For comparison with these dose-response associations, we used the same default settings when calculating BMDL results for BAEP outcomes at age 14 years.

\section{RESULTS}

Prolonged Peak III and Peak V Latencies at Higher Prenatal MeHg Exposures Were Due to Increased I-III Intervals That Were Prolonged Already 7 Years Before 
Hair-mercury concentrations at age 14 years (Table I) indicated that the children's current $\mathrm{MeHg}$ exposure had increased since the previous examination $(\mathrm{p}<0.001)$. Approximately half of the children now exceeded the hair-mercury limit of $1 \mathrm{~g} / \mathrm{g}$, but the average corresponded to only one-fourth of the concentrations in maternal hair at child birth. Nonetheless, the different sets of exposure biomarkers correlated well.

The BAEP latencies were similar to the results obtained at age $7,,^{5,18,21}$ and again differed as expected ${ }^{16}$ between boys and girls. Age had no effect within the limited range studied.

Intrauterine $\mathrm{MeHg}$ exposure biomarkers showed several statistically significant associations with the BAEP latencies, especially peaks III and V at both frequencies (Table II). The same tendency was seen for the interpeak I-III latency, despite being affected by the greater imprecision of peak I determinations. Because peak I and interpeak III-V latencies were clearly not associated with the intrauterine exposure level, $\mathrm{MeHg}$ appeared to affect mainly the I-III interval. Neither sex nor age was associated with $\mathrm{MeHg}$ exposure levels, and confounder adjustment therefore did not affect the mercury regression coefficients.

Given the more robust findings for the full peak III latency (Figure 1), its better precision, and the parallel results for this outcome obtained at age 7 years, ${ }^{5,18}$ this outcome parameter was selected for more detailed calculations. Inclusion of the postnatal exposure biomarkers as additional predictors did not affect the regression coefficients for the prenatal exposures. However, they were almost completely abolished when peak III latencies at age 7 were incorporated as predictors.

\section{Current MeHg Exposures Were Associated with Prolonged III-V Interpeak Latencies}

The regression coefficients also suggested an effect of recent $\mathrm{MeHg}$ exposure, but only on the III-V interpeak interval (Table II, Fig 2). This association was not affected by 
inclusion of prenatal exposure biomarkers, and neither did the lower mercury concentrations at age 7 seem to affect this outcome parameter. At the same time, this interpeak variable was significantly associated with all other peak latencies, except for the peak I latency.

Inclusion of $\mathrm{PCB}$ exposure within the subset of the cohort where this parameter was available did not affect any of the $\mathrm{MeHg}$ regression coefficients. In addition, the PCB parameter did not reach statistical significance in any of the analyses.

Audiometry results generally showed normal hearing, and hearing thresholds above $30 \mathrm{~dB}(\mathrm{~A})$ were recorded for only about $2 \%$ of the children. Hearing thresholds were not associated with $\mathrm{MeHg}$ exposure, except for $4 \mathrm{kHz}$ on the right ear (Table III). The association with the peak III latency (Table III) was due to a prolonged latency for peak I at increased hearing thresholds, while the interpeak I-III interval was unaffected. PCB exposure and postnatal $\mathrm{MeHg}$ exposure were not associated with the audiometry results. Inclusion of the hearing threshold at $4 \mathrm{kHz}$ as a predictor of BAEP latencies changed the mercury regression coefficients only marginally.

\section{Benchmark Dose Results Were Similar to Those Seen at Age 7 Years}

The relative magnitude of the regression coefficients (Table II) can be judged by comparison with the variability of the outcome parameters. Thus, for peak III latencies, an average regression coefficient of about 0.04 corresponds to almost $25 \%$ of the SD. Because a logarithmic transformation of the mercury concentrations was used, the effect of a doubling of the exposure can be determined by multiplying the regression coefficient by 0.301 . Accordingly, a doubling of the prenatal exposure results in a latency prolongation by about $7 \%$ of the SD. Similarly, a doubling of the current exposure level is associated with a prolongation of the interpeak III-V interval by about $5 \%$ of the SD.

Additional comparisons may be based on benchmark dose calculations. Prenatal 
BMDL results for peak III at the two frequency conditions corresponded to an average of about $10 \mathrm{~g} / \mathrm{g}$ hair based on either cord blood or maternal hair. For the III-V interval, postnatal BMDLs averaged about $5 \mathrm{~g} / \mathrm{g}$ for the child's hair-mercury concentration at age 14 years.

\section{DISCUSSION}

The developing brain is thought to constitute the most vulnerable organ in regard to $\mathrm{MeHg}$ exposure. $^{1,7}$ Emphasis in risk assessment has therefore been placed on neurological functions of children with intrauterine exposure to this neurotoxicant, and previous studies have applied neuropsychological function as a key measure of adverse effects. ${ }^{4-6}$ In parallel, neurophysiological tests, such as BAEP assessment, have found use in population studies as highly standardized, rapid, painless, and inexpensive procedures. ${ }^{16,25}$ Prolonged BAEP latencies have been reported as an effect of exposure to $\mathrm{MeHg}^{13-15}$ and other neurotoxicants, such as lead. $^{17,25}$

In the present study, we report that BAEP latency assessments were highly reproducible and that several latencies at age 14 years showed a positive association with $\mathrm{MeHg}$ exposure. Intrauterine exposure was mainly associated with delays in peaks III and V, and the I-III interpeak interval appeared to be most sensitive. This result is in accordance with previously reported exposure-associated delays in the same cohort examined at age 7 years and in a cross-sectional study of 7 -year-old children from another North Atlantic fishing population. ${ }^{18,21}$ However, the regression coefficients at age $7^{21}$ were about twice the magnitude observed seven years later. Furthermore, adjustment of the most recent peak latency for the result obtained 7 years previously virtually abolished the mercury effect. These observations suggest a lasting neurotoxic impact of the intrauterine exposure, although the reduced regression coefficient may perhaps indicate some degree of compensation. The peak III results also suggest that this 
outcome is not affected by postnatal exposures at the levels occurring in this population.

More recent $\mathrm{MeHg}$ exposure, as reflected by the current hair mercury concentrations of the children, was associated with a prolonged interpeak III-V interval. This observation is noteworthy, because the children's current exposures averaged less than one-fourth of the maternal levels during pregnancy, and a single hair analysis probably is a very inaccurate marker of the causative postnatal exposure levels. Although paired mother-child exposure data correlated well and thereby suggested relatively stable dietary habits within each household, only the recent exposure level was associated with this outcome parameter. Hair-mercury concentrations at age 7 years were the lowest and did not contribute to this association.

Despite the delayed BAEP latencies, the audiometry data suggested only limited, if any impact of $\mathrm{MeHg}$ exposure on hearing thresholds. These results parallel those obtained at age 7 years. $^{26}$ All BAEP latencies were recorded with a sound pressure adjusted for audiometry results; no association between hearing thresholds and BAEP latencies was detected, except for peak I at a single sound frequency on one side only. Although deafness has been reported in severe congenital $\mathrm{MeHg}$ poisoning cases, ${ }^{2}$ hearing loss is not a uniform finding in less serious childhood poisonings or in adult cases. ${ }^{2,27}$

The MeHg-associated prolongation of BAEP latencies in the present study was subtle and comparable to effects associated with lead exposure. ${ }^{17,25}$ These changes are much less extensive than clinical findings in patient groups, such as the abnormal BAEP waves with poorly defined or absent peaks III and V in multiple sclerosis, and the markedly prolonged interpeak latencies in patients with acoustic neurinoma or diabetes mellitus. ${ }^{28}$ However, the relative change parallels the extent of neuropsychological deficits determined in the cohort children at age 7 years. $^{5}$ Thus, in several functional domains, a doubling of the intrauterine MeHg exposure showed a decrease in performance by $5-10 \%$ of the SD. ${ }^{5,29}$ Subtle neurotoxic effects, 
sometimes expressed in terms of IQ points, have important societal implications in regard to educational achievement and earning potential. $^{30}$

The BMDL represents a statistically defined point on the dose-response curve that allows comparison between low-range toxicity studies. However, the BMDL should not be interpreted as a threshold indicator. Indeed, significant exposure-related deficits on neuropsychological tests at age 7 years were documented at maternal hair-mercury concentrations below the BMDL. ${ }^{5}$ Previous calculations ${ }^{7,12,24,31}$ based on the most sensitive neurological, neuropsychological and neurophysiological endpoints all indicate a BMDL of about $10 \mathrm{~g} / \mathrm{g}$ maternal hair, i.e., the same level as found for peak III delays at age 14 years. We found that the postnatal BMDL for the prolonged III-V interpeak interval was about one-half of that. However, due to statistical uncertainty, this difference may not necessarily reflect the relative toxic potentials of prenatal and postnatal exposures.

All observational studies have weaknesses, because all important determinants cannot be controlled a priori. However, the present study involved a large birth cohort that has been followed prospectively for 14 years and characterized in substantial detail with regard to developmental MeHg exposure levels. The participation rate at age 14 years was very high, thereby reducing the concern that the results may have been affected by differential follow-up rates. An important strength of this study is that the examinations relied on the same methodology as 7 years before, and the same examiner, who was blinded in regard to exposure data and prior peak latency results. The validity of the results was supported by extensive quality assurance data. In addition, the outcome measures were confirmed to be independent of socioeconomic confounders. The known ${ }^{16}$ BAEP peak latency difference between boys and girls was replicated, but sex was not associated with $\mathrm{MeHg}$ exposure and therefore did not cause confounding. At age 7 years, ${ }^{21}$ prolongations of the peak I latency occurred as a result of 
middle ear infection, but at age 14 years this trait was absent.

An important limitation is that only few postnatal exposure estimates were obtained and that the prenatal and postnatal exposure indicators were highly associated. Although dietary patterns may have been rather stable, the postnatal exposure biomarkers do not necessarily represent the magnitude of the toxic exposure at susceptible time windows. Any exposure misclassification would be mostly random and would tend to dilute the associations with the outcome variables, although this dilution would be limited by the wide exposure interval covered within this cohort. Despite this bias, the size of the cohort allowed separation of latency prolongations associated with intrauterine and recent MeHg exposures. The fact that peaks III and $\mathrm{V}$ at both frequencies showed clear associations with two independent indicators of prenatal MeHg exposure, and not with indicators of postnatal exposure, suggests that the findings are robust and credible for human health risk assessment. Likewise, although unanticipated, the association of the prolonged interpeak III- $\mathrm{V}$ interval with recent $\mathrm{MeHg}$ exposure only was also seen at both frequencies.

As previously reported for the results at age 7 years, ${ }^{26}$ concomitant prenatal exposure to PCBs, which occur in whale blubber sometimes eaten in the Faroes, did not influence the BAEP outcomes. Developmental exposure to PCBs is now thought to affect primarily cochlear function and impact on BAEP amplitudes rather than latencies. ${ }^{32}$ In addition, the lead exposures were comparatively low and not associated with mercury. ${ }^{19}$ The generalizability of this study would therefore not seem to be limited by concomitant exposures to other neurotoxicants.

Although a chance finding in multiple comparisons cannot be ruled out, the possibility that prenatal and postnatal $\mathrm{MeHg}$ exposure may affect different targets in the brain is supported by both experimental and clinical evidence. Thus, prenatal exposure of rats to toxic amounts of $\mathrm{MeHg}$ results in severe lesions that include the brainstem, while effects of postnatal 
treatment are less diffuse and particularly involve the sensory cortex. ${ }^{9}$ Similarly, neuropathological and imaging evidence reveals a greater degree of focal cortical damage with postnatal MeHg exposure as compared to congenital cases., ${ }^{2,3,8}$ The results of this study would therefore seem to be plausible, although the specific vulnerability of the interpeak III-V interval to postnatal $\mathrm{MeHg}$ exposure was not predicted. While the significance of postnatal $\mathrm{MeHg}$ exposure needs to be further documented in independent studies with more frequent exposure assessments, our results suggest that developmental vulnerability to $\mathrm{MeHg}$ neurotoxicity is likely to extend into the teenage period.

In conclusion, these results on EPs support the notion that intrauterine exposure to MeHg from seafood may cause lasting adverse effects on the central nervous system. They also indicate that recent $\mathrm{MeHg}$ exposure as assessed at age 14 years is associated with EP delays that differ from those incurred from exposure in utero. The possibility that peak latencies may distinguish between effects incurred prenatally and postnatally deserves attention in future studies. The potential postnatal vulnerability of the brain would mean that children ought to be protected against $\mathrm{MeHg}$ exposure to the same extent as pregnant women.

We are grateful to the cohort families for their loyal support, to the highly competent clinical staff in Tórshavn, and to Dr David A Otto for advice regarding the quality assurance for the BAEP measurements. 


\section{REFERENCES}

1. Global Mercury Assessment, United Nations Environment Programme. Geneva: UNEP, 2002. Available from URL:

http://www.chem.unep.ch/mercury/Report/Final\%20Assessment\%20report.htm (accessed, 10 January, 2003).

2. Takeuchi T, Eto K. The Pathology of Minamata Disease. A Tragic Story of Water Pollution. Fukuoka: Kyushu University Press, 1999.

3. Choi BH. The effects of methylmercury on the developing brain. Prog Neurobiol 1989; 32: 447-70.

4. Kjellström T, Kennedy P, Wallis S. Physical and Mental Development of Children with Prenatal Exposure to Mercury from Fish. National Swedish Environmental Protection Board Report No. 3642, 1989.

5. Grandjean P, Weihe P, White RF, Debes F, Araki S, Murata K, et al. Cognitive deficit in 7-year-old children with prenatal exposure to methylmercury. Neurotoxicol Teratol 1997; 19: 417-28.

6. Davidson PW, Myer GJ, Cox C, Axtell C, Shamlaye C, Sloane-Reeves J, et al. Effects of prenatal and postnatal methylmercury exposure from fish consumption on neurodevelopment: outcomes at 66 months of age in the Seychelles child development study. JAMA 1998; 280: 701-7.

7. National Research Council. Toxicological Effects of Methylmercury. Washington, DC: National Academy Press; 2000.

8. Davis LE, Kornfeld M, Mooney HS, Fiedler KJ, Haaland KY, Orrison WW, et al. Methylmercury poisoning: long-term clinical, radiological, toxicological, and pathological studies of an affected family. Ann Neurol 1994; 35: 680-8. 
9. Sakamoto M, Wakabayashi K, Kakita A, Takahashi H, Adachi T, Nakano A. Widespread neuronal degeneration in rats following oral administration of methylmercury during the postnatal developing phase: a model of fetal-type Minamata disease. Brain Res 1998; 784: $351-4$

10. FDA Consumer Advisory for Pregnant Women and Women of Childbearing Age who may become Pregnant about the Risks of Mercury in Fish. Washington, DC: Center for Food Safety and Applied Nutrition, U.S. Food and Drug Administration, 2001. Available from URL: http://www.cfsan.fda.gov/ dms/admehg.html> (accessed, 10 January, 2003).

11. The Year 2000 Freshwater Fish Consumption Advisories. Augusta, ME: Maine Bureau of Health, 2000. Available from URL: http://www.maine.gov/dhs/etp/fca.htm (accessed, 10 January, 2002)

12. Choose wisely, a health guide for eating fish in Wisconsin 2002. Madison, WI: Wisconsin Department of Natural Resources, 2002. Available from URL: http://www.dnr.state.wi.us/org/water/fhp/fish/advisories/Tables.pdf (accessed, 10 January 2003)

13. Hamada R, Yoshida Y, Kuwano A, Mishima I, Igata A. Auditory brainstem responses in fetal organic mercury poisoning. Shinkei-Naika 1982; 16: 282-5. (In Japanese)

14. Inayoshi S, Okajima T, Sannomiya K, Tsuda T. Brainstem and middle auditory evoked potentials in Minamata disease. Clin Encephalogr 1993; 35: 588-92. (In Japanese)

15. Chuu JJ, Hsu CJ, Lin-Shiau SY. Abnormal auditory brainstem responses for mice treated with mercurial compounds: involvement of excessive nitric oxide. Toxicology 2001; 162: 11-22.

16. Stockard JJ, Stockard JE, Sharbrough FW. Brainstem auditory evoked potentials in neurology: methodology, interpretation, and clinical application. In: Aminoff MJ (ed), Electrodiagnosis in Clinical neurology, $2^{\text {nd }}$ ed. New York: Churchill Livingstone, 1986; 467-503. 
17. Otto DA, Robinson G, Baumann S, Schroeder S, Mushak P, Kleinbaum D, et al. Five-year follow-up study of children with low-to-moderate lead absorption: electrophysiological evaluation. Environ Res. 1985; 38: 168-186.

18. Murata K, Budtz-Jørgensen E, Grandjean P. Benchmark dose calculations for methylmercuryassociated delays on evoked potential latencies in two cohorts of children. Risk Anal 2002; 22: 465-74.

19. Grandjean P, Weihe P, Jørgensen PJ, Clarkson T, Cernichiari E, Viderø T. Impact of maternal seafood diet on fetal exposure to mercury, selenium, and lead. Arch Environ Health 1992; 47: $185-95$.

20. Grandjean P, Weihe P. Neurobehavioral effects of intrauterine mercury exposure: potential sources of bias. Environ Res 1993; 61: 176-83.

21. Murata K, Weihe P, Araki S, Budtz-Jørgensen E, Grandjean P.. Evoked potentials in Faroese children prenatally exposed to methylmercury. Neurotoxicol Teratol 1999; 21: 471-2.

22. Hastie TJ, Tibshirani RJ. Generalized Additive Models. Boca Raton: CRC Press, 1990.

23. Crump K. Calculation of benchmark doses from continuous data. Risk Anal 1995; 15: 79-89.

24. Budtz-Jørgensen E, Keiding N, Grandjean P. Benchmark dose calculation from epidemiological data. Biometrics 2001; 57: 698-706.

25. Otto DA, Hudnell HK. Electrophysiological systems for neurotoxicity testing: PEARL II and alternatives. In: Johnson B, Anger WK, Durao A, Xintaras C (eds), Advances in Neurobehavioral Toxicology: Applications in Environmental and Occupational Health. Chelsea: Lewis; 1990; 259-76.

26. Grandjean P, Weihe P, Burse VW, Needham LL, Storr-Hansen E, Heinzow B, et al. Neurobehavioral deficits associated with PCB in 7-year-old children prenatally exposed to seafood neurotoxicants. Neurotoxicol Teratol 2001; 23: 305-17. 
27. Musiek FE, Hanlon DP. Neuroaudiological effects in a case of fatal dimethylmercury poisoning. Ear Hearing 1999; 20: 271-5.

28. Chiappa KH, Hill RA. Brainstem auditory evoked potentials: interpretation. In: Chiappa KH (ed), Evoked Potentials in Clinical Medicine, $3^{\text {rd }}$ ed. Philadelphia: Lippincott-Raven; 1997; 199-249.

29. Grandjean P, Budtz-Jørgensen E, White RF, Jørgensen PJ, Weihe P, Debes F, et al. Methylmercury exposure biomarkers as indicators of neurotoxicity in 7-year-old children. Am J Epidemiol 1999; 150: 301-5.

30. U.S.EPA. Economic analysis of toxic substances control act, Section 403: Led-based paint hazard standards. Washington, DC.: U.S. Environmental Protection Agency, 2000. Available from URL: http://www.epa.gov/opptintr/lead/403_ea_d21.pdf (accessed, 10 January 2003).

31. Crump K, Viren J, Silvers A, Clewell H 3rd, Gearhart J, Shipp A. Reanalysis of dose-response data from the Iraqi methylmercury poisoning episode. Risk Anal 1995; 15: 523-32.

32. Lasky RE, Widholm JJ, Crofton KM, Schantz SL. Perinatal exposure to Aroclor 1254 impairs distortion product otoacoustic emissions (DPOAEs) in rats. Toxicol Sci 2002; 68: 458-64. 
Table I. Results of developmental methylmercury exposure biomarkers for 859 birth cohort members without neurological disease examined at age 14 years*

\begin{tabular}{lcccc}
\hline Biomarker & $\mathbf{n}$ & $\begin{array}{c}\text { Geometric } \\
\text { average }\end{array}$ & $\begin{array}{c}\text { Interquartile } \\
\text { range }\end{array}$ & $\begin{array}{c}\text { Association with } \\
\text { cord blood } \dagger\end{array}$ \\
\hline Cord blood $(\mu \mathrm{g}$ mercury/L) & 835 & 22.6 & $13.2-40.8$ & $(1)$ \\
Hair $(\mu \mathrm{g}$ mercury/g) & 855 & 4.22 & $2.55-7.68$ & 0.77 \\
Maternal, parturition & 800 & 0.60 & $0.34-1.24$ & 0.33 \\
Child, 7 years & 839 & 0.96 & $0.45-2.29$ & 0.35 \\
Child, 14 years & & & & \\
\hline
\end{tabular}

*Concentrations in $\mu \mathrm{g}$ may be converted to nmol by multiplying by 5.0 .

$\dagger$ Correlation coefficient after logarithmic transformation. 
Table II. Mean results and regression coefficients for logarithmic transformations of mercury exposure biomarkers as predictors of latencies of brainstem auditory evoked potentials (ms) in 859 Faroese children at 14 years

\section{Regression coefficient* ( $P$ value)}

\begin{tabular}{ccccc} 
Mean (SD) & Cord blood & Maternal hair & Hair at 7 yrs & Hair at 14 yrs \\
& $(n=835)$ & $(n=855)$ & $(n=800)$ & $(n=839)$ \\
\hline
\end{tabular}

\section{$20 \mathrm{~Hz}$}

$\begin{array}{llllll}\text { I } & 1.770(0.129) & 0.015(0.213) & 0.001(0.942) & -0.005(0.622) & 0.006(0.553) \\ \text { III } & 3.952(0.161) & 0.045(0.002) & 0.037(0.014) & 0.012(0.335) & 0.001(0.907) \\ \text { V } & 5.788(0.204) & 0.049(0.006) & 0.032(0.085) & -0.002(0.901) & 0.018(0.159) \\ \text { I-III } & 2.183(0.152) & 0.027(0.051) & 0.036(0.013) & 0.017(0.150) & -0.004(0.631) \\ \text { III-V } & 1.835(0.132) & 0.004(0.722) & -0.005(0.686) & -0.014(0.181) & 0.017(0.056)\end{array}$

\section{$40 \mathrm{~Hz}$}

$\begin{array}{llllll}\text { I } & 1.806(0.169) & 0.027(0.089) & 0.014(0.410) & 0.007(0.602) & 0.012(0.293) \\ \text { III } & 4.054(0.178) & 0.032(0.048) & 0.023(0.169) & 0.008(0.536) & 0.002(0.847) \\ \text { V } & 5.954(0.214) & 0.048(0.009) & 0.036(0.066) & 0.006(0.686) & 0.024(0.070) \\ \text { I-III } & 2.248(0.190) & 0.004(0.805) & 0.009(0.614) & 0.001(0.925) & -0.010(0.430) \\ \text { III-V } & 1,900(0.148) & 0.015(0.226) & 0.013(0.383) & -0.002(0.852) & 0.022(0.028)\end{array}$

*Adjusted for sex and age; due to the logarithmic transformation of the mercury concentrations, the regression coefficient indicates the change in the dependent variable associated with an increase in $\mathrm{MeHg}$ exposure by a factor of 10 . 
Table III. Cord-blood mercury concentration (geometric mean) and peak III latency of the brainstem auditory evoked potentials measured at age 14 years (arithmetic means) in 857 Faroese cohort children in relation to the hearing threshold at $4 \mathrm{kHz}$ on the right ear.

\begin{tabular}{ccccc}
\hline $\begin{array}{c}\text { Hearing } \\
\text { threshold } \\
{[\mathbf{d B}(\mathbf{A})]}\end{array}$ & $\mathbf{n}$ & $\begin{array}{c}\text { Mercury } \\
\text { concentration** }\end{array}$ & & \multicolumn{2}{c}{ Peak III latency (ms) } \\
\cline { 4 - 5 } & 158 & 20.0 & $\mathbf{2 0 H z}^{* * *}$ & $\mathbf{4 0} \mathbf{H z}^{* * *}$ \\
\hline 0 & 171 & 20.8 & 3.94 & 4.03 \\
0 & 218 & 22.8 & 3.92 & 4.02 \\
5 & 161 & 24.9 & 3.94 & 4.03 \\
10 & 136 & 25.4 & 3.99 & 4.09 \\
\hline 10 & & & 3.98 & 4.10 \\
\hline
\end{tabular}

$P$ value for association (Spearman's correlation coefficient) with hearing threshold:

$* *<0.01 ; * * *<0.001$ 


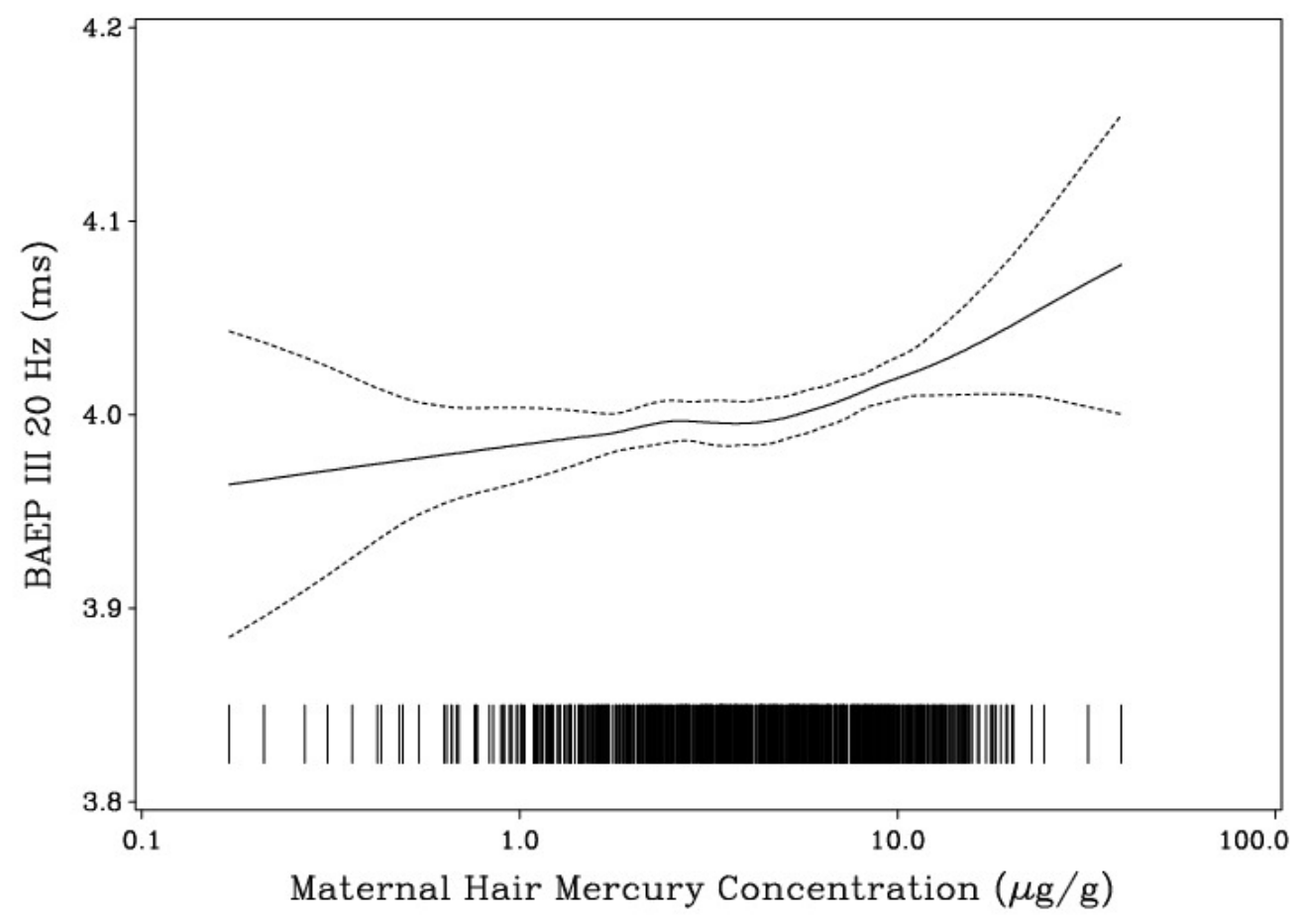

Fig 1. Prenatal dose-effect relationship between maternal hair mercury at birth and the peak III latency of the brainstem auditory evoked potentials in 859 Faroese children at 14 years adjusted for sex and age. The association is estimated in a generalized additive model analysis in which a smooth nonparametric curve (equivalent degrees of freedom, 3) is fitted to the data while adjusting for confounders. The broken lines indicate the pointwise $95 \%$ confidence interval for the dose-response relationship. Each vertical line above the horizontal axis represents one observation at the exposure level indicated. To convert to nmol/g, multiply mercury concentration in $\mu \mathrm{g} / \mathrm{g}$ by 5.0 . 


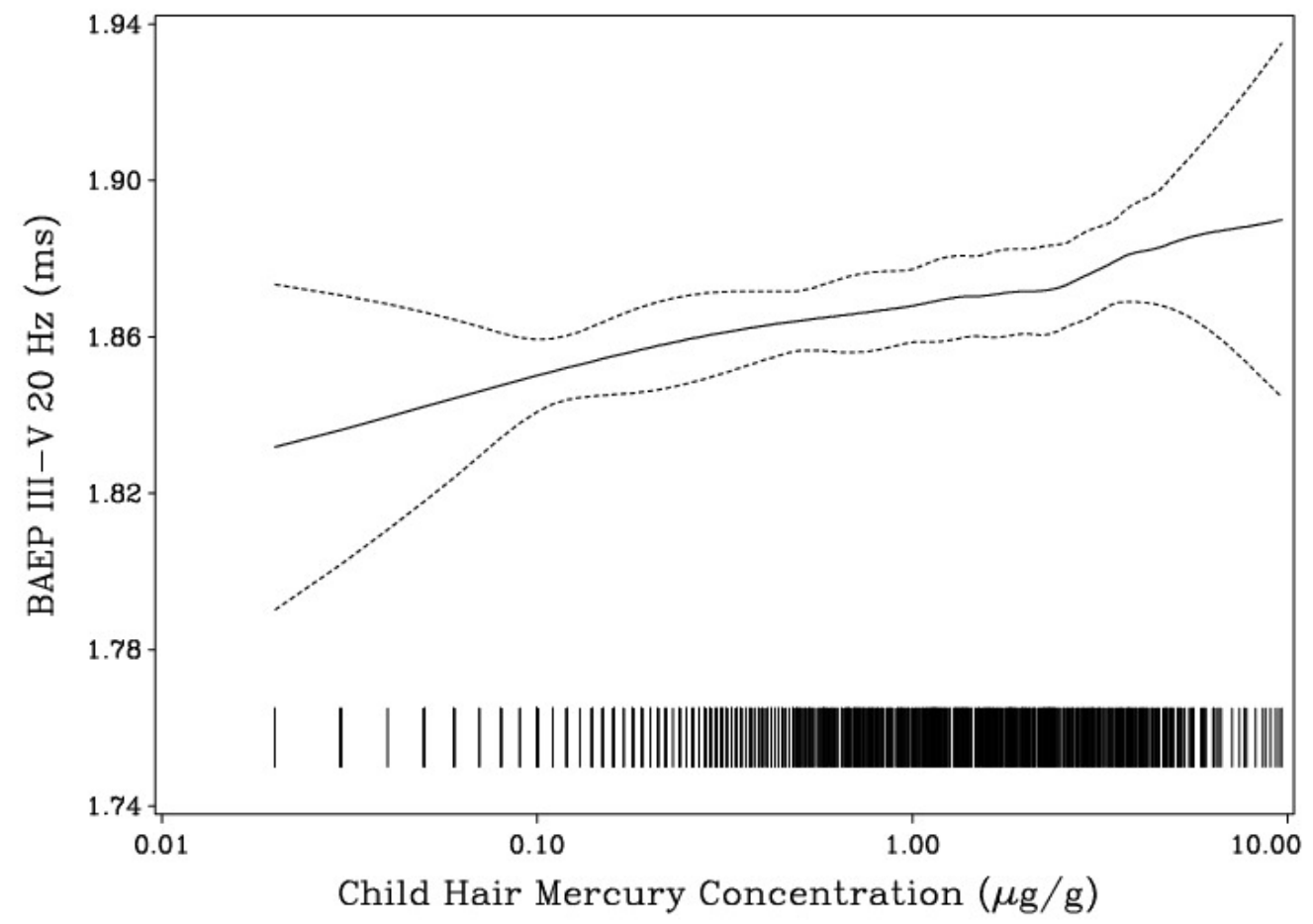

Fig 2. Postnatal dose-effect relationship between the child's current hair mercury and the interpeak III-V latency of the brainstem auditory evoked potentials in 859 Faroese children at 14 years adjusted for sex and age. The association is estimated in a generalized additive model analysis as in Figure 1, but the horizontal scales differ. The broken lines indicate the pointwise $95 \%$ confidence interval for the dose-response relationship. Each vertical line above the horizontal axis represents one observation at the exposure level indicated. To convert to nmol/g, multiply mercury concentration in $\mu \mathrm{g} / \mathrm{g}$ by 5.0 . 